\title{
Espécies novas da flora amazônica (Ebenaceae)
}

Paulo B. Cavalcante (")

\section{Resumo}

Ultimamente as coletas botânicas na regiāo amazônica vêm sendo incrementadas graças a esforços conjuntos de várias instituiçōes. Em consequiência, os herbários regionais cresceram sensivelmente e o material botânico neles depositado tem revelado muita novidade, sejam espécies novas ou raras. No presente trabalho, o autor descreve cinco novas espécies de Diospyros (Ebenaceae): D. piresii, D. froesii, D. landii, D. miltonii e D. uaupensis.

Desde a nossa última publicação sobre o gênero Diospyros (Cavalcante, 1966), as coleções dos herbários INPA, MG e IAN vêm crescendo sensivelmente, principalmente em decorrência dos convênios firmados entre o INPA e NYBG para coletas botânicas intensivas e exaustivas na região amazônica, tendo à frente o botânico Ghillean T. Prance. Por outro lado a atuação do RADAM na região, através do seu setor de vegetação, tem facilitado a visita de coletcres botânicos a lugares de difícil acesso. ou mesmo inacessíveis, a não ser pelos meios de que dispõe essa instituição como sejam, helicópteros e pequenos aviōes. Como resultado dessa colaboração, volumosas coleções vêm sendo depositadas nos herbários acima referidos. Os estudos preliminares desse material vem despertando o maior interesse pelas novidades que encerram, sejam espécies novas ou raras ou novos dados para auxiliar na interpretação dos tipos de vegetação. No gênero Diospyros (Ebenaceae), verificou-se, entre as inúmeras amostras examinadas, algumas espécies seguramente novas, a seguir descritas, deixando-se, porém, de lado, aquelas que ainda não puderam ser identificadas, ou descritas como novas, dada a deficiência do material.
Diospyros piresii P. Cavalcante, n. sp. (Est. 1)

Arbuscula $4 \mathrm{~m}$ alta trunco $20 \mathrm{~cm}$ diametro. ramis junioribus (fructiferis) dense fulvo-tomentosis demum glabris. Folia: petiolus supra plano-canaliculatus $10-13 \mathrm{~mm}$ longus $2-2,2 \mathrm{~mm}$ diametro; lamina coriacea, oblonga vel oblanceolata, ad basin acuta, ad apicem acuminata, $18-22 \mathrm{~cm}$ longa, $4,5-5,5 \mathrm{~cm}$ lata, supra glabra, nitens, infra palida, sparce tomentosa sed ad nervos dense tomentosa; costa mediana supra canaliculata, subtus prominens; nervi laterales utrinque circiter 11-13, arcuate adscendentes, eis minoribus reticulatis utrinque prominulis. Flores non suppetebant. Fructus immaturi 1-2 in axillis foliorum orti, ovati, $2 \mathrm{~cm}$ alti, $1,5 \mathrm{~cm}$ diametro, loculis 7-8 unispermis; calyx in fructu persistens, tubo $2 / 3$ longitudine sepali equante: sepalum fructiferum rigide coriaceum, triangulare, apice attenuato, pungente, extus ad partem mediana imprimis ad basin depressum, utrinque dense tomentosum.

Species haec a speciebus amazonicis bene distincta, fructibus $D$. tenuiflorae A. C. Smith aliquam similis sed foliis valde distincta.

BRASIL. Estado do Acre, margem da estrada Cruzeiro do Sul, $30 \mathrm{~km}$ da cidade. L. R. Marinho 104 (IAN, HOLÓTIPO). Árvore de $4 \mathrm{~m}$ e $60 \mathrm{~cm}$ de circunferência, 11 fev. 1976 (fr.). Ibidem, O. P. Monteiro \& C. Damião 240 (MG, INPA). 10 fev. 1976 (fr.).

Arvoreta de $4 \mathrm{~m}$ de altura, tronco $\mathrm{com} 20 \mathrm{~cm}$ de diâmetro, ramos novos (frutíferos) densamente fulvo-tomentosos, depois glabros. Folha: pecíolo plano-canaliculado, $10-13 \mathrm{~mm}$ de comprimento, 2-2,2 $\mathrm{mm}$ de diâmetro; lâmina coriácea, oblonga ou oblanceolada, ápice acuminado, base aguda, $18-22 \mathrm{~cm}$ de comprimento, $4,5-5,5 \mathrm{~cm}$ de

(*) - INPA - Museu Paraense Emílio Goeldi, Belém, PA. 


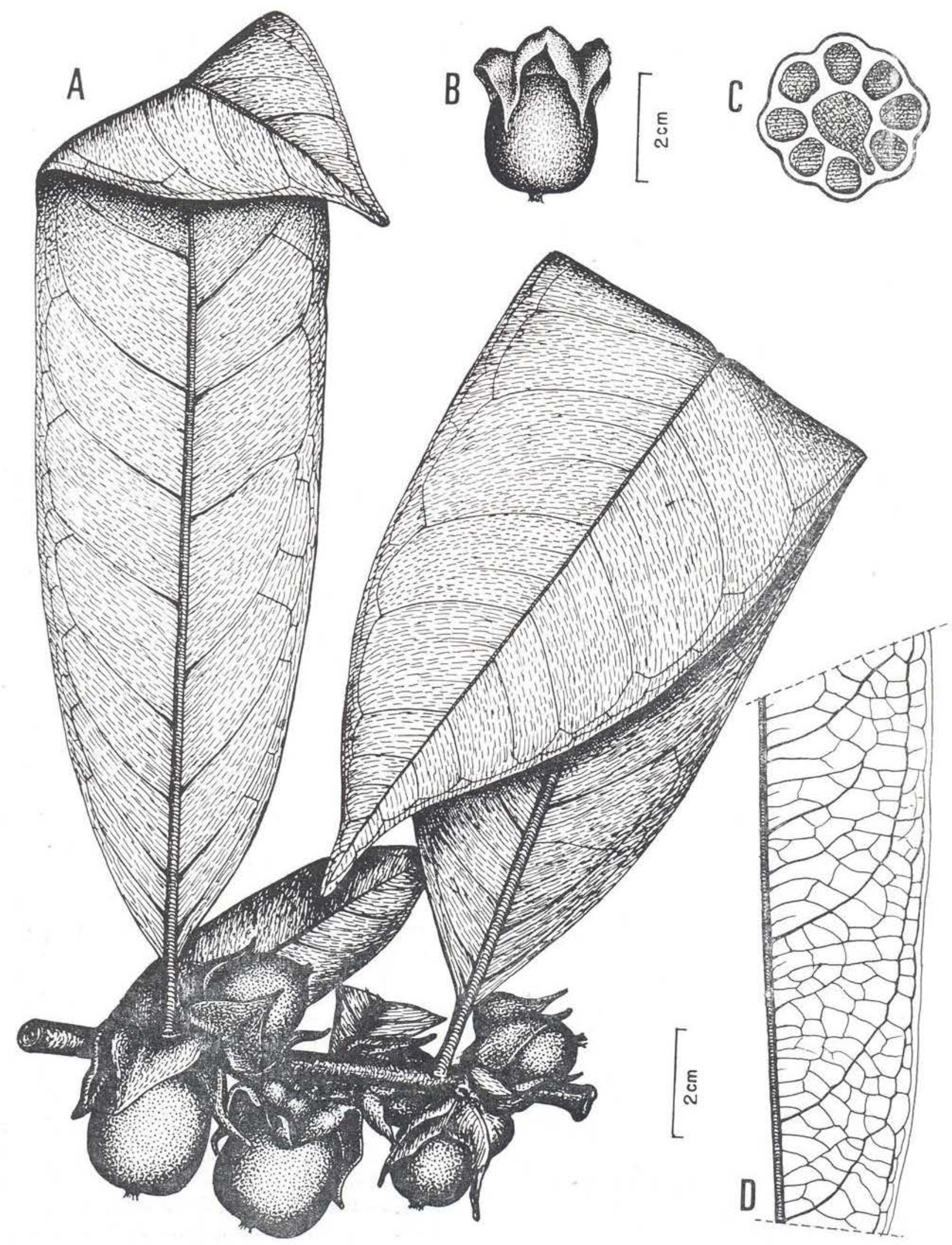

Est. 1 - Diospyros piresii: A) ramo frutífero; B) fruto; C) corte do fruto; D) detalhe de nervação (Des. R. Alvarez). 
largura, face superior glabra e brilhosa, face inferior opaca, esparso-tomentosa exceto nas nervuras onde os pêlos são adensados: nervura central supra canaliculada, infra proeminente; nervuras laterais 11,13 pares, arqueadas. ascendentes e, como a reticulação, supra e infra promínulas. Flores, não vistas. Fruto (imaturo) 1-2 na axila de folhas, ovalado, $2 \mathrm{~cm}$ de altura e $1,5 \mathrm{~cm}$ de diâmetro, com 7-8 lóculos unispermos; cálice com o tubo igual a $2 / 3$ do comprimento da sépala; sépala rígido-coriácea triangular, de ápice afilado, ponteagudo, com a região mediana depressa, principalmente junto à base, denso-tomentoso dentro e fora.

Esta nova espécie é bem distinta de todas as outras espécies amazônicas; os frutos têm alguma semelhança com os de $D$. tenuiflora, mas as folhas diferem em todos os aspectos.

Nome dedicado ao amigo, Prof. João Murça Pires, chefe do Departamento de Botânica do Museu Goeldi, sem favor algum, o mais seguro conhecedor da flora amazônica.

Diospyros froesii P. Cavalcante, n. sp. (Est. 2)

Arbor parva (fide Fróes); rami teretes atrobadii, glabri: Folia: petiolus $10-12 \mathrm{~mm}$ longus $4 \mathrm{~mm}$ diametro; lamina subcoriacea late ovata $32-35 \mathrm{~cm}$ longa, $17-20 \mathrm{~cm}$ lata, apice acuto, basi rotundata, subtus griseo-badia, microscopice pubescens superficie papillis densiter obtecta, supra badio-rubescens, glabra; nervus centralis (medianus) supra impressus, subtus prominens. sparse tomentosus; nervi secundarii (laterales) utrinque 12-14, leviter arcuati et distincte proper marginem anastomosantes, supra impressi subtus prominentes; nervi tertiari inter secundarios plus minusve perpendiculariter transversi. Flores ignoti. Fructus (immaturi solum visi) rotundati, in apice leviter depressi, $4 \mathrm{~cm}$ diametro, pericarpio lignoso, ruguloso, calycibus persistentibus rigidis, sepalis 5 , loculis ut videtur 6 monospermis.

Floribus ignotis affinitas huius speciei dubia est.

BRASIL. Amazonas, rio Solimões, São Paulo de Olivença. R. L. Fróes 20800 (IAN, HOLÓTIPO), abril, 1945 (fr.).
Árvore pequena (segundo Fróes), ramos cilíndricos, pardo-escuros, glabros. Folha: pecíolo 10-12mm longo $4 \mathrm{~mm}$ diâmetro; lâmina subcoriácea, largo-ovalada, $32-35 \mathrm{~cm}$ longa, $17-20$ $\mathrm{cm}$ larga, ápice agudo, base arredondada, face inferior pardo-cinza, microscopicamente pubescente e denso-papilosa, face superior pardoavermelhada, glabra; nervura central supra impressa, infra proeminente, esparso-tomentosa; nervuras laterais 12-14 pares, levemente arqueadas e nitidamente anastomosadas junto à margem, supra impressas e infra proeminentes; nervuras terciárias dispostas entre as secundárias em ângulo mais ou menos reto formando retânguios. Flores $\delta$ e $\&$ não vistas. Fruto: (imaturo) arredondado, levemente depresso, $4 \mathrm{~cm}$ de diâmetro, pericarpo lenhoso, ruguloso, cálice persistente, rígido, com 5 sépalas, lóculos vistos 6 , unispermos.

A ausência de flores não permite o estabelecimento da afinidade desta nova espécie com outras. A forma, o tamanho e o revestimento das folhas, bem como a constituição lenhosa do pericarpo são bem distintos de todas as espécies conhecidas.

O nome da espécie é dedicado à memória de seu coletor, Ricardo de Lemos Fróes, que por muitos anos estudou a fiora amazônica.

Diospyros landii P. Cavalcante, n. sp. (Est. 3)

Arbor $8 \mathrm{~m}$ alta rami juniores leviter fracti flexi, gracili, tomentosi, plus minusve adpressi; internodii $18-20 \mathrm{~mm}$ longi, eis superioribus $\mathrm{mi}$ noribus c. $12-14 \mathrm{~mm}$ longis. Folia: petiolus supra plano-canaliculatus, dense tomentosus, $5-7 \mathrm{~mm}$ longus, $1 \mathrm{~mm}$ diametro; lamina rigide chartacea, lanceolata vel anguste lanceoiata, c. $6-7,3 \mathrm{~cm}$ longa et $2-2,7 \mathrm{~cm}$ lata (raro $3-4 \mathrm{~cm} \times$ $1,2-1,5 \mathrm{~cm})$, ad basin acuta interdum obtusa, leviter decurrens, ad apicem acuminata, ad margines leviter revoluta, supra glabra, microscopice rugulosa, sparse tomentosa pilis adpressis; nervus principalis supra impressus subtus prominulus; nervi secundarii subtus conspicui supra indistincti. Flores (masculi soli visi): inflorescentia cymosa, congesta 8-12 flora; pedicelus dense tomentosus pilis adpressis: calyx campanulatus $3 \mathrm{~mm}$ altus, denti- 
bus 4-5 triangularibus $1 \mathrm{~mm}$ altis extus adpresse tomentosus; corolla subrotata petalis 5 ad basin adnatis, tubo $1,3 \mathrm{~mm}$ aito, lobis $5 \mathrm{~mm}$ longis et $2,3 \mathrm{~mm}$ latis, oblongo-ellipticis, intus glabris, extus vitta pilosa mediana basale $2 / 3$ longitudinis loborum (pilis adpressis) ornatis; stamina circiter 27, ad basin corollae tubi adnata, 2,3mm longa, filamentibus $0,5-0,8 \mathrm{~mm}$

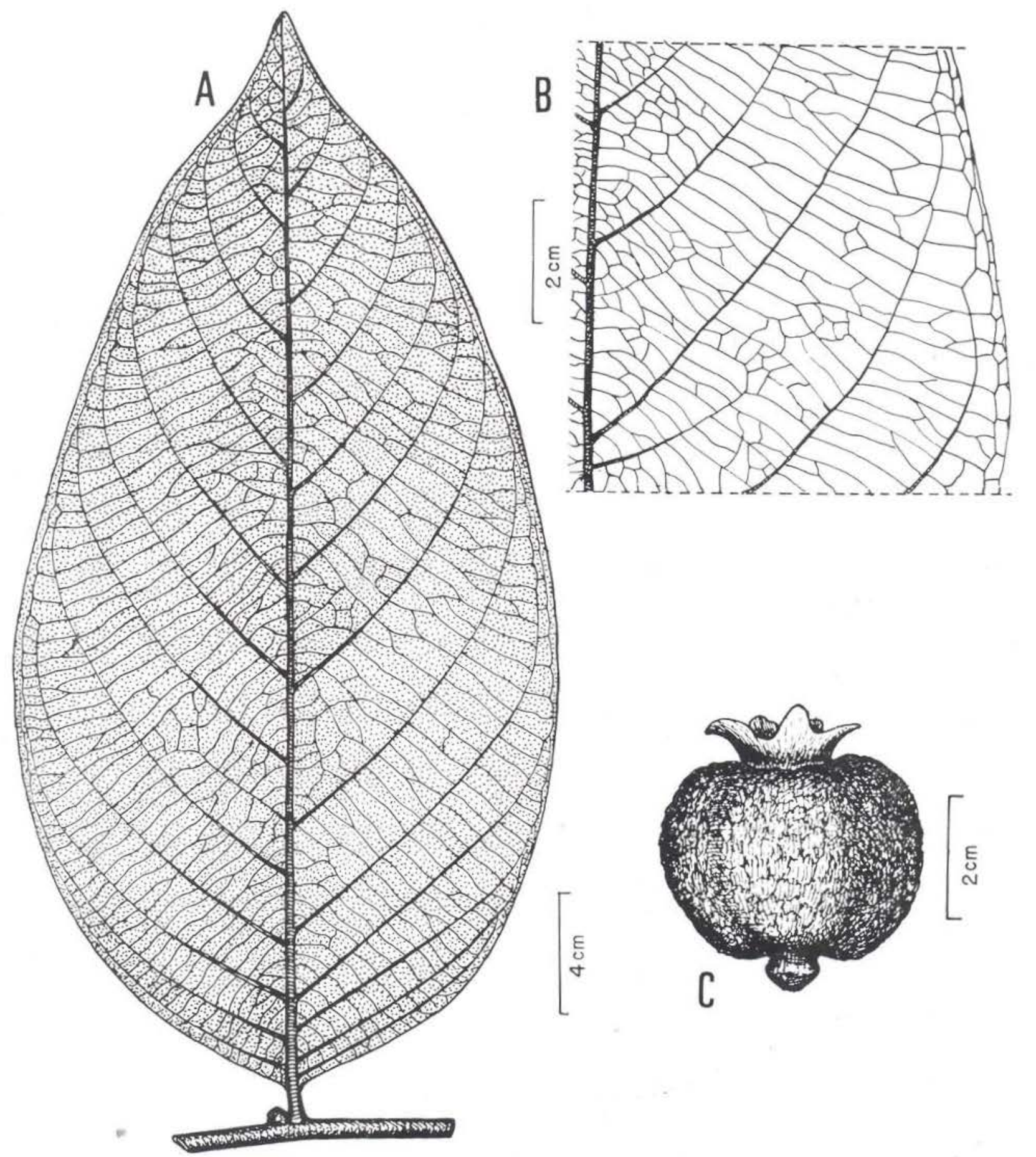

longis, connectivo dense adpresse sericeo; ovarii rudimentum absens.

D. praetermissae Sandw. affinis sed insertione foliorum, magnitudine florum, numero staminum et indumento facile dignoscenda.

BRASIL. Estado do Acre, Município de Brasiléia, seringal Montevidéo. N. T. Silva 3512

Est. 2 - Diospyros froesii: A) folha; B) detalhe de nervação; c) fruto. (Des. R. Alvarez). 


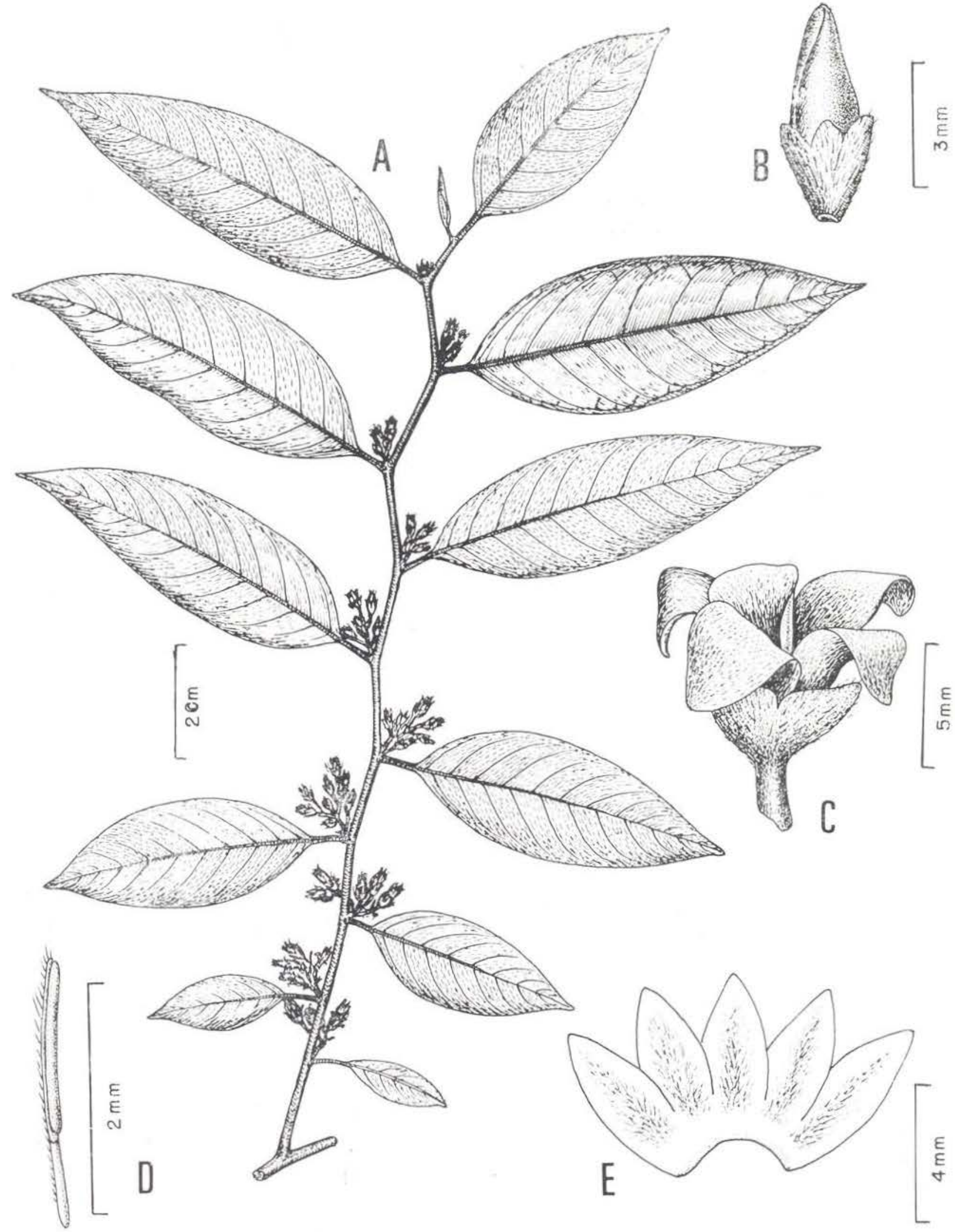

Est. 3 - Diosıyros landii: A) ramo florífero; B) botã floral; C) flor; D) estame; E) corola distendida. (Des, R, Alvares), 
(IAN, HOLÓTIPO). Árvore de $8 \mathrm{~m}$ e $15 \mathrm{~cm}$ de diâmetro; flor masculina branca, 16 jul. 1972. Ibidem, J. M. Pires \& N. A. Rosas 13690 (IAN) (estéril), jul. 1972.

Árvore de $8 \mathrm{~m}$ alta; ramos jovens levemente fractiflexos, delicados, tomentosos, sub-adpressos; internós $18-20 \mathrm{~mm}$, nas extremidades 12-1.7 $\mathrm{mm}$. Folha: pecíolo supra plano-canaliculado, denso tomentoso, $5-7 \mathrm{~mm}$ longo, $1 \mathrm{~mm}$ diâmetro; lâmina firme cartácea, lanceolada ou estreitolanceolada, $6-7,3 \mathrm{~cm}$ longa, $2-2,7 \mathrm{~cm}$ lata (raro $3-4 \mathrm{~cm}$ por $1.2-1,5 \mathrm{~cm}$ ), base aguda, até obtusa, levemente decorrente, ápice acuminaao, margens leve-revolutas, face superior glabra, minuto-rugulosa e negrescente quando seca, face inferior pardo-purpurescente, esparso-tomentosoadpressa; nervura principal supra impressa e infra promínula, nervuras secundárias visiveis apenas na face inferior. Flores: ( $\delta$ ) Inflorescência cimosa, condensada, com 8-12 flores, pedicelo denso-tomentoso-adpresso; cálice campanulado, $3 \mathrm{~mm}$ de altura, com 4-5 dentes triangulares, de $1 \mathrm{~mm}$ alto, tomentoso-adpresso por fora; corola subrotada, com 5 pétalas soidadas na base, em tubo de $1,3 \mathrm{~mm}$ de altura, lobos $5 \mathrm{~mm}$ longos por 2,3mm latos, oblongo-elípticos, glabros por dentro, adpresso-pubescentes por fora ao longo da região central do terço supe rior, para a base; estames em torno de 27 , in seridos na base do tubo da corola, variando $c$. $2-3 \mathrm{~mm}$ de comprimento (filetes de $0,5-0,8 \mathrm{~mm}$ ) conectivo denso adpresso-sericeo; ovário rud. mentar ausente.

O nome desta nova espécie é dedicado a Antonio José Landi, italiano (bolonhês), arquiteto régio do século 18 , o qual fixou residência em Belém, Pará, por mais de 30 anos. Além de sua contribuição à arquitetura regional estudou a flora e a fauna da Amazônia e os manuscritos e ilustraçōes desse estudo, até então inéditos, tornam-se, agora, conhecidos através dos pesquisadores Augusto Meira Filho e Osvaldo Rodrigues da Cunha, este, zoólogo do Museu Paraense Emilio Goeldi.

\section{Diospyros miltonii P. Cavalcante, n. sp (Est. 4)}

Frutex vel arbor parva circiter $4 \mathrm{~m}$ alta; rami teretes junioribus puberulis. Folia: petiolus $5-8 \mathrm{~mm}$ longus, supra canaliculatus; lam:- na discoloris, subcoriacea interdum coriacea lanceolato-oblonga, $20-28 \mathrm{~cm}$ longa et $6,5-8 \mathrm{~cm}$ lata, basi acuta, apice acuminato, supra glabra, badio cinerea et opaca, subtus castanea, adpresse pubescens, margine valde revoluta; nervus principalis (medianus) supra impressus subtus prominens; nervi secundarii (laterales) utrinque circiter 14-18 in superficiebus ambabus laminae foliorum indistincti. Inflorescencia axillaris, 3-4-floris, floribus in cymis parvis dispositis; bracteae ellipticae $11 \mathrm{~mm} \times 8 \mathrm{~mm}$ metientes, ut bracteolis extus adpresse tomen. tosae. Flores masculi (in alabastro); calyx campanulatus, crassus, extus dense adpresse pilosus, intus parce adpresse pubescens; tubus circiter $6 \mathrm{~mm}$ altus; lobi deltoidei apice acuto, $2 \mathrm{~mm}$ alti, 2,5-3mm ad basin lati, margine revo. iuta; corolia in alabastro $7-8 \mathrm{~mm}$ long9, tubo adpresse piloso, 3--4mm longo, lobis 4-5 asymetricis, crassis, carnosis circiter $3 \mathrm{~mm}$ latis, apice acuto vel vix acuminato, extus dense sericeo, intus glabro; stamina circiter 50 e basi $2 \mathrm{~mm}$ in tubo adnato, $3,5 \mathrm{~mm}$ longa, connectivo dense sericeo; flos masculos ovarii rudimento praeditus; flores feminei ignoti.

Floribus $D$. peruvianae affinis, habitus $D$. discolori ex insulis Phillipinas similis sed ambibus speciebus plurimis characteribus differt.

BRASIL. Pará, Altamira, km 74 da estrada Transamazônica, no rumo de Itaituba; mata virgem baixa e seca. P. Cavalcante \& Milton $G$ Silva, 2772 (MG HOLÓTIPO). Arbusto de 4m, folha verde-escura, flor amarelada.

Arbusto ou pequena árvore, cerca de $4 \mathrm{~m}$; ramos cilíndricos, os mais jovens pubérulos. Folha: pecíolo 5-8mm longo, supra canaliculado. lâmina discolor, subcoriácea a coriácea, lanceolado-oblonga, $20-28 \mathrm{~cm}$ longa, $6,5-8 \mathrm{~cm}$ larga, base aguda e ápice acuminado, face superior glabra, pardo cinza (in sicco) e opaca, face inferior acastanhada, adpresso-pubescente, margens fortemente revolutas; nervura principa! supra impressa e infra proeminente; nervuras laterais cerca de 14-18 pares, algo obscuras em ambas as faces. Inflorescência axilar, em pequenas cimas de 3-4 flores; brácteas elíticas, de $11 \mathrm{~mm}$ por $8 \mathrm{~mm}$, bractéolas $8 \mathrm{~mm}$ por $5 \mathrm{~mm}$. ambas adpresso-tomentosas por fora. Flor masculina (botão): cálice campanulado, espes so, densamente adpresso-piloso por fora par. 


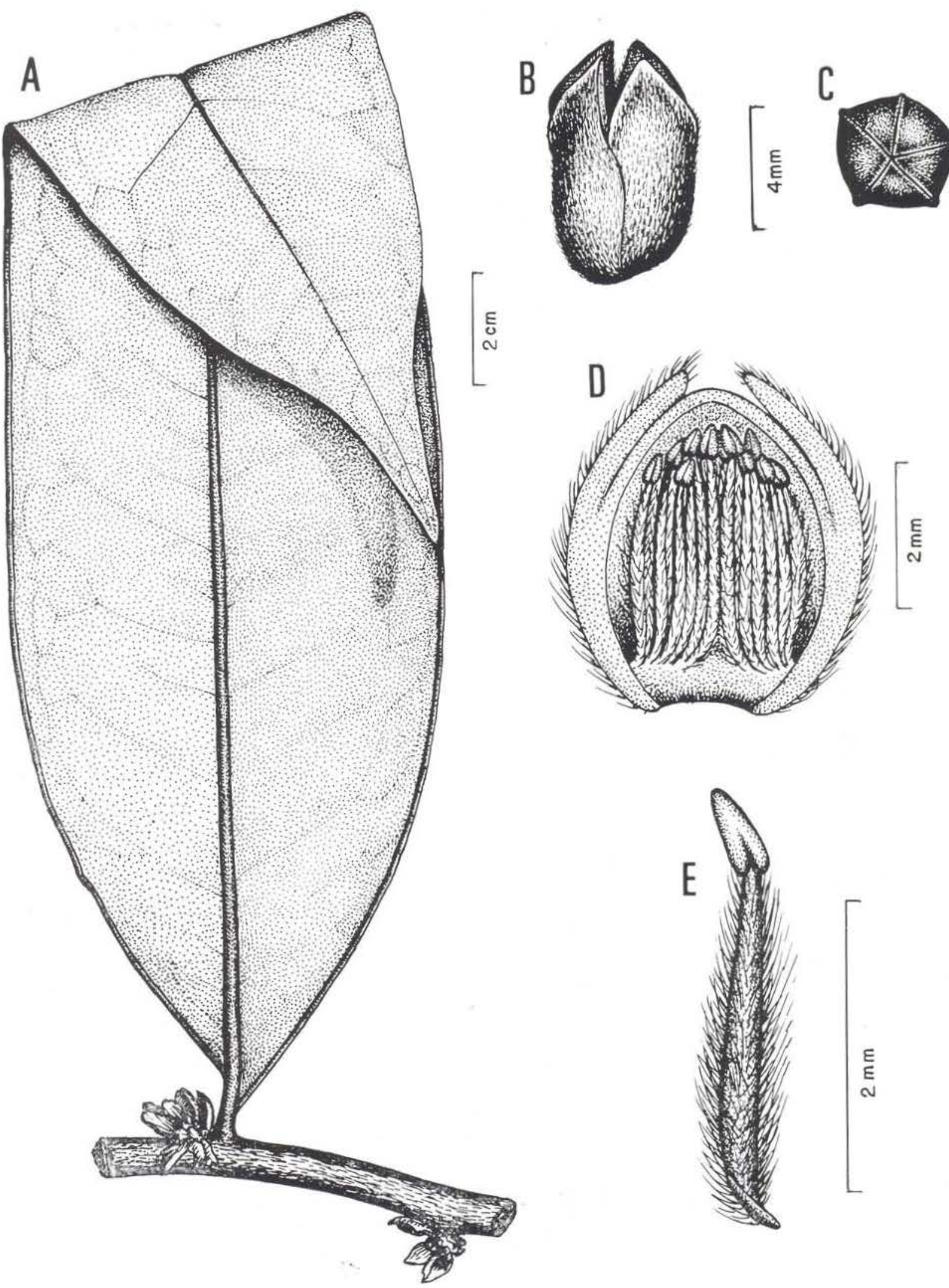

Est. 4 - Diospyros miltonii: A) folha; B) cálice; C) botão; D) corte longitudinal do botão floral; E) estame. (Des. R. Alvarez). 


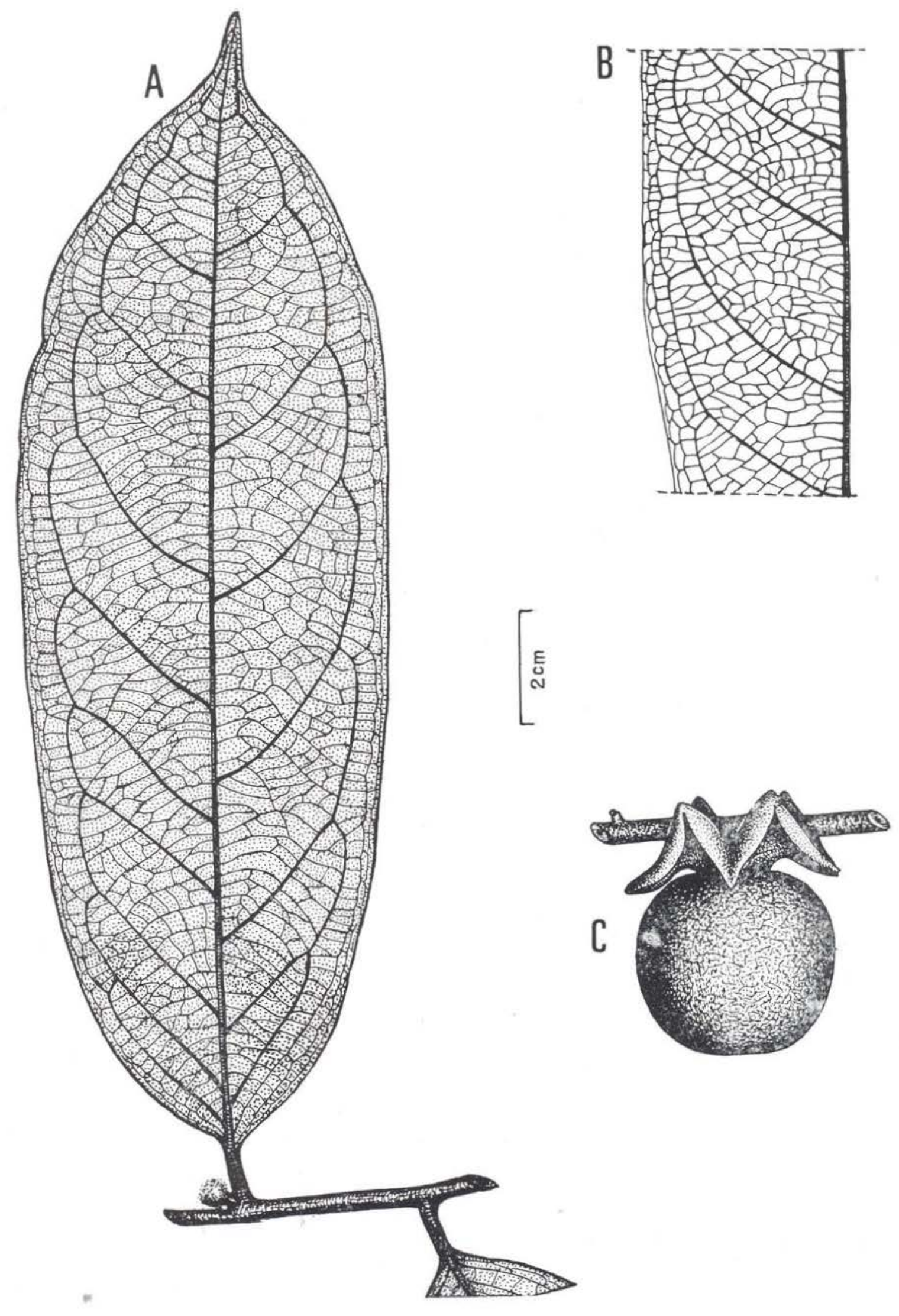

Est. 5 - Diospyros uaupensis: A) folha; B) detalhe de nervaçăo; C) fruto. (Des. R. Alvarez). 
cialmente adpresso-pubescente dentro; tubo cerca de $6 \mathrm{~mm}$ de altura; lobos deltoides, com apice agudo, $2 \mathrm{~mm}$ de altura e $2,5-3 \mathrm{~mm}$ de largura na base, margens revolutas; corola em botão, $7-8 \mathrm{~mm}$ de altura; tubo adpresso-piloso. $3-4 \mathrm{~mm}$ de altura, lobos 4-5, assimétricos, espesso-carnosos, cerca de $3 \mathrm{~mm}$ de largura, ápice agudo ou minuto-acuminado, densamente adpresso-seríceo por fora, glabro dentro; estames cerca de 50 , inseridos na parede do tubo a $2 \mathrm{~mm}$ da base, $3,5 \mathrm{~mm}$ de comprimento, conectivo denso-seríceo; flores masculinas com rudimento de ovário presente; flores femininas e frutos, ausentes.

Pelas flores, tem certa afinidade com $D$. peruviana ¿, pelo hábito, assemelha-se com D. discolor, das ilhas Filipinas, entretanto, por muitos caracteres difere de ambas as espécies.

O nome da nova espécie é dedicado ao nosso auxiliar e coletor botânico Milton Gonçalves da Silva.

Diospyros uaupensis $\mathrm{P}$. Cavalcante, n. $\mathrm{sp}$. (Est. 5)

Arbor circiter $7 \mathrm{~m}$ alta, trunco $10 \mathrm{~cm}$ diametro. Folia: petiolus $10-15 \mathrm{~mm}$ longus $2,5-3 \mathrm{~mm}$ diametro, supra canaliculatus, pubescens: lamina $13,5-20 \mathrm{~cm}$ longa et $5-7,5 \mathrm{~cm}$ lata, rigide coriacea, oblonga vel oblongo-lanceolata, ad basin obtusa vel obtuso-rotundata, ad apicem caudata et plicata, margine leviter revoluta; nervus centralis supra impressus, subtus prominens; nervi secundarii (lateralis) numerosi subtus elevati supra in depressionibus laminae prominuli bullas parvas formans. Flores non visi. Fructus sessili, rotundati, circiter $3 \mathrm{~cm}$ diametro, in siccitate epicarpio nigrescenti, ad apicem depressi vel leviter attenuati, calycibus persistentibus, lignosis lobis 4 , triangularibus valde replicatis, loculis ut videtur 7 (8?) .

Textura et nervatione foliorum $D$. bullatae A. C. Smith affinis sed a speciebus congeneribus imprimis forma fructuum glabrorum bene distincta.

BRASIL. Amazonas, rio Negro, Uaupés, rodovia Perimetral Norte. O. C. Nascimento et al., 4 (IAN, HOLÓTIPO). Abril, 1975 (fr.). Rio Negro, São Gabriel da Cachoeira (Uaupés), a $45 \mathrm{~km}$ da estrada Perimetral Norte, mata de terra firme. M. R. Cordeiro 345 (IAN), árvore de $6 \mathrm{~m}$ e $5 \mathrm{~cm}$ de diametro, $26 \mathrm{fev} .1975$ (fr).

Árvore cerca de $7 \mathrm{~m}$ de altura, tronco com $10 \mathrm{~cm}$ de diâmetro, ramos jovens glabrescentes. Folha; peciolo $10-15 \mathrm{~mm}$ longo, 2,5-3mm de diâmetro, supra canaliculado, pubescente; lâmina $13,5-20 \mathrm{~cm}$ de comprimento, $5-7,5 \mathrm{~cm}$ de largura, rígido-coriácea, oblonga ou oblongolanceolada, base obtusa ou obtuso-arredondada, ápice caudado-plicado, margem levemente revoluta; nervura central supra impressa e infra proeminente, nervação secundária copiosa, saiiente na face inferior e promínula no fundo de depressões, na face superior formando pequenas bolhas. Flores ausentes. Fruto séssil, arredondado, cerca de $3 \mathrm{~cm}$ de diâmetro, epicarpo enegrecido quando seco, ápice achatado ou levemente apontado, cálice persistente, lenhoso, com 4 lobos triangulares, fortemente replicados, lóculos visto 7 (8 ?).

Espécie bem distinta das demais, aproximando-se de $D$. bullata pela consistência das folhas e nervação, mas a forma e os frutos glabros na nova espécie são inconfundíveis.

\section{AGRADECIMENTO}

Ao Dr. João Murça Pires, Chefe do Departamento de Botânica do Museu Goeldi, pela colaboração na versão das diagnoses para o latim.

\section{Summary}

The collections of Diospyros (Ebenaceae) recently made in the Amazonian Region include many interesting species. Among them the author recognises five new species he describes herein: D. piresii, D. landii, D. froesii, D. miltonii and $\mathbf{D}$. uaupensis.

\section{BIBLIOGRAFIA CITADA}

Cavalcante, paulo B.

1966 - Duas novas espécies do gênero Diospy. ros Dalech. (Ebenaceae) na Amazônia. Bol. Mus. Par. Emílio Goeldi, n.s., Bot., 22:1-6, il. 